Disponível em:

http://editora.unoesc.edu.br/index.php/race

RACE, Joaçaba, v. 16, n. 3, p. 185-208, edição especial, 2017

\title{
CAPACITAÇÃO NO SETOR PÚBLICO: ANALISANDO O PROCESSO DE UMA IFES
}

Capacitation in the public sector: analising an Ifes process

\section{Antônio Raimundo Cardoso Teixeira Filho}

E-mail: antonior79@gmail.com

Especialista em Gestão de Pessoas pela Universidade Federal da Bahia; Mestrando em Administração no Núcleo de Pós-graduação em Administração da Escola de Administração da Universidade Federal da Bahia; Administrador pela Escola de Administração da Universidade Federal da Bahia. Endereço para contato: Avenida Reitor Miguel Calmon, s/n, Vale do Canela, 40110903, Salvador, Bahia, Brasil.

Denise Ribeiro de Almeida

E-mail: deniserib@gmail.com Doutora em Administração pela Escola de Administração da Universidade Federal da Bahia; Mestre em Administração pela Universidade Federal do Rio de Janeiro; Professora na Escola de Administração da Universidade Federal da Bahia e na pós-graduação do Núcleo de Pós-graduação em Administração da Escola de Administração da Universidade Federal da Bahia.

Leonardo Ribeiro de Almeida

E-mail: leoribal@gmail.com Graduado em Administração Pública pelo Centro de Ciências Jurídicas e Políticas da Universidade Federal do Estado do Rio de Janeiro.

Susan Mary Vieira de Almeida

E-mail: smva@ufba.br

Especialista em Metodologia do Ensino, Pesquisa e Extensão em Educação pela Universidade do Estado da Bahia; Mestranda em Administração pelo Núcleo de Pós-graduação em Administração da Escola de Administração da Universidade Federal da Bahia; Assistente em Administração pela Universidade Federal da Bahia.

Artigo recebido em 22 de agosto de 2017. Aceito em 13 de novembro de 2017. 


\section{Resumo}

Um dos marcos legais da adoção de modelos gerenciais na gestão de pessoas da administração pública brasileira foi a política de desenvolvimento de pessoas por meio da capacitação, trazida com o Decreto n. 5.707/2006. Nesse contexto, neste trabalho tomou-se como objeto a Universidade Federal da Bahia, com o objetivo de descrever e analisar o processo de capacitação implementado à luz da PNDP, caracterizando o modelo utilizado pela Instituição para capacitar o corpo técnico-administrativo, bem como os indicadores resultantes dessas ações institucionais. Para tanto, foi realizada análise de documentos institucionais, como também da literatura sobre o tema, a fim de se reunirem os elementos necessários às análises que deram respostas à questão de pesquisa. Assim, foram utilizadas também as técnicas de observação ativa e entrevistas informais. Os principais achados dizem respeito à formalização do modelo de capacitação na UFBA, à descrição quantitativa de servidores atendidos e aos impactos nos indicadores institucionais. $\mathrm{O}$ trabalho tem limitações em face ao escopo de atores institucionais participantes da pesquisa, sugerindo-se novos estudos com as percepções de atores e IFES não contemplados no estudo.

Palavras-chave: Gestão de pessoas no serviço público. Capacitação nas IFES. Política pública.

\section{Abstract}

One of the most important legal frameworks of personal management in Brazil's Public Management was the policy of people's development based on 5.707/2006's decree. In this respect, this paper analyzes Universidade Federal da Bahia aiming the analyzis of PNDP's qualification process, describing the applied method and its results. For this purpose, the institutional documents and the theme's literature were analyzed making possible the analyzis that helped to answer this paper's questions. Therefore, live observation and casual interviews were also utilized. The main findings are related to the formalization of UFBA's qualification model, quantitative description of served employees and guiding indicators'impact. The main limitations are related to the scope of the institutional actors of this research, consequently new studies with different actors, IFES and perceptions are recommended.

Keywords: Personnel management on public service. IFES' qualification. Public policies.

\section{INTRODUÇÃO}

O Estado brasileiro, conforme Bresser-Pereira (2007, 2009) e Abrucio (2007, 2011), passa por inúmeras transformações a partir da segunda metade do século XX, visando adaptar-se às mudanças emanadas por novas demandas sociais, que atribuem mais importância à efetividade das ações da área pública, associada à busca pela qualidade dos serviços públicos ofertados e ao uso racional dos recursos disponíveis. 
Esse contexto de maior profissionalização da administração pública, segundo Guimarães (2000) e Bergue (2011), caracteriza-se por transformações tecnológicas, sociais e econômicas, as quais, em conjunto, levam à adoção de novos padrões e modelos de gestão das organizações públicas. Esses autores afirmam, ainda, tratar-se de um processo de reestruturação produtiva que tem como bases o desenvolvimento científico, tecnológico e a consolidação dos chamados mercados globais. Diante desses desafios, o setor público precisa alterar seus padrões de atuação, transformando modelos organizacionais ancorados em estruturas burocráticas e rigidamente hierarquizadas, em modelos mais flexíveis e adaptáveis às mudanças mais profundas e aceleradas.

Em consonância com tais concepções, Bresser-Pereira (2007, 2009) e Abrucio (2007, 2011) afirmam que o Brasil faz uma transição entre o modelo Burocrático, adotado a partir do primeiro Governo Vargas, com a criação do Departamento de Administração do Serviço Público (DASP), órgão responsável pela implantação dos princípios hierárquicos e centralizadores da burocracia clássica na administração pública, e o modelo gerencialista. Este último tem como primeira iniciativa, ainda que incipiente, o Decreto-Lei n. 200/1968, que visava superar a rigidez burocrática. Contudo, esse objetivo começa a ser efetivamente alcançado, a partir de 1995, com a implementação do Plano Diretor da Reforma do Aparelho do Estado (PDRAE). Destaca-se que este último Plano põe em curso na administração pública, por meio da consolidação do uso de técnicas e ferramentas usuais da iniciativa privada, o foco gerencial.

Nos anos 2000, como afirmam Bergue (2011) e Teixeira Filho e Almeida (2014), a partir do primeiro mandato do presidente Luís Inácio Lula da Silva, ganha força a concepção da importância da formulação de políticas públicas que visem, para além de garantir a recomposição, permitir a real valorização dos diferentes quadros de pessoal do setor público nacional. Essa visão de política pública culmina com a publicação da Política Nacional de Desenvolvimento de Pessoal da administração pública direta, autárquica e fundacional (PNDP). Complementando a análise desse contexto, segundo Bregalda, Tosta e Dalmau (2014), a PNDP busca sistematizar a capacitação dos servidores a partir de demandas reais para, assim, permitir a melhoria contínua do desempenho organizacional.

Nesse cenário de modernização da administração pública, em geral, e da gestão de pessoas, no particular, a Universidade Federal da Bahia (UFBA) inicia uma reforma para modernizar sua estrutura de gestão de pessoas a partir de 2006, com a criação da Pró-Reitoria de Desenvolvimento de Pessoas (PRODEP). Com tal objetivo, a instituição implementa a PNDP, em 2008, implantação inicialmente operacionalizada por meio da reformulação do instrumento de avaliação do desempenho dos servido- 
res técnico-administrativos em educação (TAE) e, também, pela oferta de um leque diversificado e amplo de ações de capacitação para tais quadros, esforço consolidado em 2009 com a elaboração e execução do seu primeiro Plano de Capacitação (PAC).

Com base nesse contexto inicial, neste estudo buscou-se analisar o modelo de implementação da PNDP na UFBA, refletindo sobre os avanços e limitações encontrados nesse processo. Assim, a questão de pesquisa foi: Como se deu o processo de capacitação dos servidores TAEs na UFBA, no período 2009-2016? Ressalta-se que a escolha por esse período decorreu por ele representar o início da sistematização na organização do PAC, bem como o final do último PAC, totalmente concluído. Aponta-se que essa caracterização e reflexões são feitas com base na análise de documentos institucionais e na visão de atores envolvidos no processo de capacitação da UFBA.

Como objetivo geral, o trabalho se propõe a analisar o modelo de capacitação utilizado para o quadro de servidores TAE pela UFBA, tendo como objetivos específicos: caracterizar o processo de capacitação desses servidores, analisar a evolução dos indicadores de capacitação deles a partir da execução da PNDP e propor ações para suprir as lacunas existentes na implementação da PNDP na UFBA. Tem-se neste estudo, como pressuposto básico, a visão de que há, ao longo do período 2009-2016, pouca aderência entre os objetivos estratégicos organizacionais e o modelo de capacitação implantado na UFBA.

Ressalta-se que este estudo faz parte de um projeto mais amplo desenvolvido por seus autores, o qual visa contribuir para a ampliação do conhecimento da gestão de pessoas no setor público em geral e, especificamente, no contexto de uma IFES, tomando-se por base as especificidades inerentes a tais organizações. Dessa forma, busca suprir uma lacuna existente no que se refere à capacitação na administração pública, como apontam os achados de estudo feitos por Almeida, Brauer e Pinheiro Júnior (2017), os quais demonstram a presença nas bases Spell e Anpad de apenas 42 artigos sobre o tema, no período 2000-2015.

Finaliza-se esta introdução pontuando-se que o artigo prossegue com a apresentação do referencial teórico composto de conceitos e modelos acerca do processo de capacitação na administração pública brasileira, no geral, e nas IFES, em particular. Sua terceira seção explicita a metodologia utilizada na sua construção, bem como a caracterização da organização e do seu setor responsável pela capacitação. Em sequência apresenta-se o processo de capacitação adotado na UFBA e são trazidas algumas reflexões sobre ele, tomando-se por base o referencial discutido. Finaliza-se o artigo com algumas considerações finais, suas limitações e a apresentação de possíveis trabalhos futuros que dele podem ser desdobrados. 


\section{CAPACITAÇÃO NA ADMINISTRAÇÃO PÚBLICA BRASILEIRA}

A administração pública no Brasil vem se adaptando, ao longo do tempo, à evolução dos aspectos políticos e econômicos que permeiam o contexto de atuação do Estado. Para Bresser-Pereira (2007, 2009) e Abrucio (2007, 2011), nessa evolução há três momentos de mudanças mais sensíveis no setor público: a reforma Burocrática de 1936; a reforma de 1967, com a tentativa de descentralização e desburocratização; e a reforma iniciada nos anos 1990, com a implementação da administração pública gerencial em resposta à crise do Estado da década de 1980 e à globalização da economia.

Ainda para os últimos autores, historicamente no caso brasileiro, a administração pública burocrática foi inicialmente adotada em substituição à patrimonialista, modelo no qual os patrimônios público e privado tinham fronteiras tênues, e o Estado era entendido como propriedade do seu maior mandatário. Com o correr dos anos, ao se esgotarem no campo organizacional o modelo burocrático e, no campo político, o modelo intervencionista, ganha força o gerencialismo, fortalecendo no País a importância de a esfera pública pautar-se pelos pressupostos da Nova Gestão Pública (NGP).

Para Camões (2013), em consonância com Bresser-Pereira (2007, 2009), a primeira tentativa de reforma de estado com viés gerencial no Brasil ocorre em 1967, com a publicação do Decreto-Lei n. 200, que promoveu a descentralização político-administrativa na busca pela rigidez da administração indireta e da maior eficiência da administração descentralizada. Para Bresser-Pereira (2007, 2009), a reforma administrativa proposta por esse Decreto fracassou, agravando a situação da administração pública, já degenerada pela crise política do regime militar do final dos anos de 1970 e início dos anos de 1980. Avançando-se no tempo, tem-se, em Abrucio (2007, 2011), que a mais recente reforma do Estado se inicia na década de 1990, combinando dois fenômenos: a crise do regime autoritário e o declínio do modelo nacional desenvolvimentista, tendo como um dos seus pilares, ainda durante o Governo do presidente Fernando Henrique Cardoso, as ações concebidas e operacionalizadas pelo Ministério da Administração e Reforma de Estado (MARE), sob o comando do ministro Bresser-Pereira, com vistas a promover a implantação da NGP no Brasil.

Ainda na década de 1990, conforme Schikmann (2010), Pantoja et al. (2012) e Bregalda, Tosta e Dalmau (2014), implementam-se diversas ações com o objetivo de promover melhorias na gestão dos recursos humanos da administração pública brasileira, na busca por torná-la mais eficiente. Dentre estas, destacam-se a adequação das carreiras dos servidores à nova realidade, com a adoção de gratificação de desempenho; um modelo de capacitação que permita a progressão funcional e maiores con- 
tribuições à organização; incentivos diversos ao desenvolvimento horizontal e vertical na carreira, entre outras.

Desse modo, para Pantoja et al. (2012) e Teixeira Filho e Almeida (2014), com a consolidação da administração pública gerencial no País, resultante da necessidade da adoção de mudanças para atender às demandas sociais cada vez mais complexas, o setor público experimentou uma nova realidade institucional, onde parâmetros de eficiência, eficácia e efetividade das ações passam a ser vistos como básicos, diante da necessidade de racionalização dos gastos públicos e da melhoria na qualidade dos serviços prestados à sociedade em geral.

A fim de garantir o alcance de tais objetivos, segundo Bergue (2011) e Cavalcante et al. (2016), a ferramenta da capacitação, antes utilizada no setor privado para qualificar o empregado, visando exclusivamente maximizar o lucro das organizações, passa a ser empregada na administração pública. Contudo, o foco dessa última é diverso, não podendo ser descrito como a busca exclusiva pelo resultado financeiro em si. O que se procura é a garantia de prestação de um serviço público de qualidade, ao tempo em que se contemple maior eficiência e eficácia no uso dos diferentes recursos pelas instituições públicas, já que estas também precisam ser autofinanciáveis.

Nos anos 2000, o presidente Luís Inácio Lula da Silva, segundo os autores anteriormente citados, promoveu a reformulação do serviço público, realizando novos concursos, reestruturando algumas carreiras do funcionalismo e buscando a recomposição salarial. Nesse contexto, para responder adequadamente à nova realidade e atender ao grau de exigência do cidadão usuário dos serviços públicos, no final do seu primeiro mandato, promulgou a PNDP por meio do Decreto n. 5.707/2006. Essa legislação, em seu art. $2^{\circ}$, define a capacitação como o processo permanente e deliberado de aprendizagem com o propósito de contribuir para o desenvolvimento de competências institucionais por meio do desenvolvimento de competências individuais (BRASIL, 2006).

Segundo Pantoja et al. (2012) e Cardoso (2017), a PNDP desempenhou papel fundamental na construção de novos perfis de qualificação profissional no serviço público, na transição de um modelo burocrático para um modelo de gestão baseado em resultados. Desse modo, pode-se depreender que a PNDP introduz práticas da gestão estratégica de pessoas ao serviço público, ao atrelar a capacitação da força de trabalho e o desenvolvimento na carreira aos objetivos institucionais, e impactos na melhoria da qualidade dos serviços prestados. Complementando tal concepção, Amaral (2006) afirma que a PNDP, por sua visão estratégica, concebe o processo de mudança da gestão pública como viável, apenas tomando por base a inovação, o aprimoramento 
da capacidade de atendimento, a inclusão de servidores e a mobilização e retenção dos seus talentos, entre outras dimensões igualmente importantes.

Avançando no que se refere às reflexões acerca da operacionalização do processo de capacitação, Schikmann (2010), Bergue (2011) e Pacheco et al. (2008) pontuam que seu objetivo é desenvolver uma força de trabalho dotada das competências necessárias ao atendimento dos diferentes objetivos organizacionais, para, assim, permitir o alcance dos objetivos e metas estabelecidos no planejamento estratégico organizacional.

Sob tal prisma, a capacitação é vista como um processo contínuo que deve acompanhar a evolução da organização, considerando as mudanças requeridas e o suprimento de novas competências que emergem de um contexto em transformação no qual as organizações atuam. Assim, para que seu processo de operacionalização atenda às demandas organizacionais, pontuam Pacheco et al. (2008) e Schikmann (2010) ser fundamental sua aderência ao preconizado no planejamento estratégico da organização.

Visando atender a tais desafios, no que se refere à sua capacidade de adaptação a tal cenário, o processo de capacitação, segundo os últimos autores, deve englobar, para além de cursos direcionados à qualificação voltada à execução de atividades mais cotidianas, a realização, por parte dos servidores, de cursos de graduação e pós-graduação que lhes permitam desenvolver competências compatíveis àquelas demandadas pela organização, tanto no momento presente quanto em projeções de demandas futuras, expressas no seu planejamento estratégico.

Com vistas a sistematizar uma proposta de operacionalização, Pacheco et al. (2008, p. 57) afirmam ser importante a utilização do modelo 5W2H - What? (objetivo), Why? (justificativa), How? (ações formais e informais e modelo de avaliação), Who? (identificação dos responsáveis), When? (definição de prazos), Where? (definição de locais) e How much? (quantificação dos diferentes recursos envolvidos).

Especificamente referente às IFES, a promulgação da Lei n. 11.091 de 2005, que instituiu o plano de carreira dos servidores TAEs, de acordo com Cavalcante et al. (2016) e Cardoso (2017), incentivou-as a adotarem a prática da oferta de cursos de capacitação voltados para o corpo técnico, considerando que esse plano de carreira trazia um incentivo financeiro aos servidores por vincular a mudança do seu padrão de vencimento à participação em cursos de capacitação em determinado período. Portanto, ainda segundo os autores, a progressão na carreira ocorreria, entre outros fatores, em razão das certificações adquiridas em ações de capacitação. 
Adicionalmente, Schikmann (2010) e Oliveira Filho (2012) afirmam que essa Lei estabeleceu novos paradigmas para a estruturação de cargos dessas instituições, com a hierarquia entre eles agregando critérios que contemplavam não apenas as exigências de escolaridade para o exercício das atividades, mas também outros requisitos e habilidades necessários para a execução de atividades específicas. Ainda segundo eles, a edição da Lei n. 11.784/2008 tem o mérito de sistematizar um modelo de avaliação de desempenho centrado no monitoramento sistemático da atuação individual do servidor, tomando como referências de controle as metas estabelecidas nos respectivos planos de trabalho.

Tais iniciativas impactaram os departamentos de pessoal das IFES e se somaram à PNDP, o que, para Oliveira Filho (2012), trouxe como inovação o estímulo no que se refere à busca individual pelos programas de capacitação para o desenvolvimento de competências individuais e institucionais. Para Bregalda, Tosta e Dalmau (2014), tal política agregou valor à estratégia organizacional, permitindo que os servidores das IFES estivessem mais aptos a enfrentar os desafios inerentes à NGP.

Complementando essa visão acerca da capacitação, Ayres (2012, 2015), Cardoso (2017) e Almeida, Brauer e Pinheiro Júnior (2017), além de apontarem para o fato de o conceito de capacitação ser um conceito polissêmico, reforçam que o processo de capacitação por competências deve, obrigatoriamente, superar a visão tradicional de treinamento do servidor, por exigir que a organização faça um diagnóstico de suas demandas atuais e futuras à luz dos seus objetivos, para, a partir de então, elaborar um programa de capacitação que contribua para o desenvolvimento individual e institucional.

Sob uma perspectiva mais instrumental, Camões (2013) sinaliza que dentre as diretrizes da PNDP estão a promoção de ações de capacitação aos servidores, a garantia de acesso aos eventos de capacitação, o estímulo à participação e a contemplação do resultado das ações de capacitação associado à mensuração do desempenho do servidor, essas duas vistas como complementares entre si.

Finalizando esta seção do artigo, com base em Oliveira Filho (2012), Ayres (2012, 2015), Camões (2013) e Cardoso (2017), considera-se que esse novo conjunto legal da área de gestão de pessoas tem exigido que as IFES estejam dispostas a pôr em curso um processo de mudança de cultura, uma vez que a implantação das ações de capacitação deve ser pautada pela análise conjunta das demandas do planejamento estratégico organizacional e daquelas que emergem dos anseios individuais dos funcionários a serem capacitados. Para esses autores, tal movimento consiste em profis- 
sionalizar o servidor para alcançar os objetivos institucionais, ao tempo em que lhe permita prestar um serviço de qualidade para a sociedade a quem serve.

Ainda em consonância com os últimos autores, nesse cenário as IFES enfrentam dificuldades de naturezas diversas para implantar a citada política, destacando-se aquelas de ordem estrutural e sistêmica, sobre as quais se busca discutir de forma mais detalhada no escopo da pesquisa de campo que compõe este estudo. A seguir, apresenta-se o percurso metodológico adotado na construção do trabalho, assim como a caracterização da UFBA e do setor estudado.

\section{METODOLOGIA E ORGANIZAÇÃO ESTUDADA}

Quanto aos objetivos, a pesquisa é descritiva, uma vez que, para Gil (2002), descrevem-se as características de determinado fenômeno com a utilização de técnicas padronizadas de coleta de dados. No caso deste estudo, descreveu-se o processo de capacitação dos servidores TAEs da UFBA, analisando-se os resultados e dificuldades desse processo.

Quanto à abordagem, é qualitativa, pois, conforme Godoy (1995), são obtidos dados descritivos sobre determinado processo, pelo contato direto do pesquisador com o fenômeno estudado. Além disso, segundo Gil (2008), são analisados dados sem a necessidade de se amparar em análises estatísticas. Em relação ao delineamento, fez-se um estudo de caso, pois, segundo Yin (2005), trata-se de uma pesquisa empírica que investiga fenômenos contemporâneos em profundidade, em uma organização específica, sendo operacionalizada por meio do uso da triangulação de instrumentos, com vistas a garantir maior fidedignidade aos dados e análises apresentados ao leitor.

Para o cumprimento dos objetivos do presente estudo, fez-se uma pesquisa documental no Núcleo de Capacitação (NUCAP) da Coordenação de Desenvolvimento Humano (CDH) da Pró-Reitoria de Desenvolvimento de Pessoas (PRODEP) da UFBA. Nessa fase, tomaram-se por base documentos institucionais (planos anuais de capacitação, relatórios de execução de ações de capacitação, relatórios de gestão da PRODEP, relatórios institucionais disponibilizados na internet e o Plano de Desenvolvimento Institucional da UFBA), considerando-se o período 2009-2016. Outra técnica utilizada na coleta de dados foi a aplicação de entrevistas informais com os trabalhadores do NUCAP para, ainda segundo Gil (2008), obter-se uma visão geral da problemática pesquisada.

No que se refere à organização estudada, segundo informações do seu sítio eletrônico, as origens da UFBA remontam à fundação da Escola de Cirurgia da Bahia, 
primeiro curso universitário do Brasil, em 1808, por Dom João VI. Ainda no século XIX, incorporou alguns cursos - Farmácia (1832) e Odontologia (1864), Academia de Belas Artes (1877), Direito (1891) e Politécnica (1896) -, sendo posteriormente agregadas outras instituições independentes durante os 40 primeiros anos do século XX.

Em 1946, o professor Edgard Santos liderou o processo de federalização da instituição, implantando a infraestrutura física e de pessoal, adotando o modelo de universidade que integrava as áreas de conhecimento de Artes, Letras, Humanidades e Ciências. Nesse mesmo ano, a Universidade da Bahia constitui-se formalmente. Em 1950, passa a ser denominada Universidade Federal da Bahia, integrando as escolas isoladas e instituindo outros cursos. Atualmente, a UFBA possui mais de 40 mil alunos matriculados em 99 cursos de graduação e pós-graduação em dois campi localizados em Salvador e Vitória da Conquista. A instituição possuía, em 2016, um total de 5.719 servidores, sendo 2.524 servidores da carreira docente e 3.195 servidores técnico-administrativos.

Já a Pró-Reitoria de Desenvolvimento de Pessoas (PRODEP) surge em 2006, no contexto de mudanças na gestão de pessoas no serviço público. Desde então, tem entre outras atribuições, a responsabilidade de propor, planejar, articular, implementar e gerenciar programas e projetos voltados para o desenvolvimento e a capacitação dos servidores da UFBA, articulados e integrados com a gestão de desempenho e a obtenção da eficácia dos processos de trabalho, visando à consecução dos objetivos institucionais. Sua estrutura é composta pelas Coordenações de Gestão de Pessoas (CGP), que operacionalizam os processos de admissão, benefícios e folha de pagamento, e de Desenvolvimento Humano (CDH), responsável pelos processos de capacitação, qualidade de vida no trabalho e seleção.

Entre os núcleos administrativos da CDH está o NUCAP, órgão responsável por planejar, coordenar, executar e avaliar ações de capacitação com base na legislação vigente, assim como selecionar as modalidades de eventos de capacitação mais adequadas às demandas da instituição, considerando os recursos orçamentários disponíveis. O núcleo é composto por cinco servidores de carreira e um funcionário terceirizado. Três servidores são mestres e dois são especialistas. Na sequência, apresentam-se os resultados obtidos na pesquisa de campo.

\section{ANÁLISE E DISCUSSÃO DOS DADOS}

Considera-se, aqui, em consonância com o sinalizado por Oliveira Filho (2012), Ayres (2012, 2015), Camões (2013), Bregalda, Tosta e Dalmau (2014) e Car- 
doso (2017), como uma estratégia organizacional a ser seguida a formalização do Plano de Carreira dos Cargos Técnico-Administrativos em Educação (PCCTAE), instituído pela Lei n. 11.091, de 12 de janeiro de 2005. Assim, ao ser operacionalizado, esse Plano demandou uma remodelagem administrativa e de conhecimento referente aos paradigmas que alicerçaram, até então, a condução da Gestão de Pessoas na UFBA, com o objetivo de melhor direcionar seu quadro funcional para o bom desempenho das funções institucionais. Além disso, a promulgação da PNDP, por meio do Decreto n. 5.707 em 2006, levou a Instituição a investir em ações de capacitação para o corpo funcional, ainda que elaboradas de forma isolada e, assim, contrariando o que os autores preconizam como fundamental ao processo de capacitação institucional.

Avançando historicamente, tem-se 2007 como o marco da divulgação pela PRODEP do primeiro programa de capacitação com alguns cursos voltados ao aprimoramento de tarefas dos servidores, seguindo-se a mesma tendência 2008, pois somente em 2009 a PRODEP elaborou o primeiro PAC da UFBA, adequando procedimentos com vistas a alinhar as práticas de treinamento e desenvolvimento à PNDP e institucionalizar a política de capacitação de pessoal da IFES.

Pontua-se que o PAC é considerado um dos instrumentos da referida política, conforme disposto no artigo $5^{\circ}$ do Decreto n. 5.707/2006, devendo, como afirmam Camões (2013), Bregalda, Tosta e Dalmau (2014) e Cavalcante et al. (2016), congregar ações de capacitação e educação formal, denominadas na PNDP como ações de qualificação e qualidade de vida no trabalho. Na sequência, o artigo analisa algumas das características vistas como mais relevantes nos PAC operacionalizadas pela UFBA, no período 2009-2014.

\subsection{ANÁLISE DOS PLANOS ANUAIS DE CAPACITAÇÃO (PAC)}

Da análise dos PAC da UFBA é possível se identificar que sua elaboração ocorre em sintonia cada vez maior ao longo do tempo, com o que lecionam Schikmann (2010), Bergue (2011), Pacheco et al. (2008) e Camões (2013). Tal percepção decorre de se verificar que, ao serem concebidos, tomam por base as diferentes demandas institucionais identificadas por meio de três inputs complementares: um instrumento interno denominado de Levantamentos de Necessidade de Capacitação (LNC); as solicitações diretas feitas pelas unidades de ensino e órgãos administrativos e de apoio; e as análises dos relatórios de execução do PAC anterior. Pontua-se que até 2016 foram realizados quatro LNC na IFES; no Quadro a seguir descrevem-se os levantamentos 
realizados em cada um dos anos, assim como se apresenta o método usado para a informação dos cursos ofertados e a coleta dos dados relativos aos cursos desejados.

Quadro 1 - LNC realizados pela UFBA de 2009 a 2016

\begin{tabular}{|c|c|}
\hline \multirow{2}{*}{ Ano } & \multicolumn{1}{c|}{ Método de coleta de dados utilizado } \\
\hline 2009 & $\begin{array}{l}\text { Formulário impresso enviado às unidades universitárias. Neste, o dirigente máximo ou seu } \\
\text { representante indicava os cursos que deveriam ser ofertados aos servidores. }\end{array}$ \\
\hline 2011 & $\begin{array}{l}\text { Formulário nos mesmos moldes do aplicado em 2009, contudo, fruto da análise do docu- } \\
\text { mento anterior e dos PAC operacionalizados; acrescentou-se uma lista de cursos elaborada } \\
\text { pela PRODEP, para servir de proposta inicial para os demandantes. }\end{array}$ \\
\hline 2014 & $\begin{array}{l}\text { Levantamento presencial realizado com os representantes das unidades universitárias que } \\
\text { tivessem uma atuação enquanto agentes de gestão de pessoas. Mais uma vez, utilizou-se } \\
\text { uma listagem de cursos elaborada pela PRODEP, listagem essa neste momento já ampliada. }\end{array}$ \\
\hline $\begin{array}{l}\text { Banco de dados informatizado contendo os cursos a serem ofertados disponibilizado aos } \\
\text { listagem elaborada pela PRODEP, os gestores optavam por ações de capacitação para cada } \\
\text { um dos TAEs pertencentes à sua equipe de trabalho. }\end{array}$ \\
\hline
\end{tabular}

Fonte: elaborado pelos autores a partir dos relatórios de Gestão da PRODEP.

Apesar da aderência ao que preconiza o referencial anteriormente mencionado, não se pode deixar de apontar que, da análise da evolução do processo de operacionalização dos LNC, depreende-se a ausência de uniformidade metodológica ao longo do período estudado. Para além dessa consideração, os autores deste artigo entendem que tal característica pode ser compreendida como um reflexo do amadurecimento desse processo na UFBA, não sendo, assim, algo totalmente negativo no modelo de capacitação institucional adotado.

Contudo, ao se refletir acerca do conteúdo contido em cada um dos instrumentos aplicados no levantamento de demandas, verifica-se que os cursos indicados pela PRODEP, nas listas disponibilizadas aos gestores da UFBA, versam, em sua maioria, sobre temas genéricos e pouco vinculados às atividades cotidianas ou às necessidades de capacitação da organização. Dentre estes, podem ser citados: gestão de pessoas, gestão pública, biossegurança e informática.

Em síntese, os PAC executados pela PRODEP são compostos por cursos que exploram conteúdos relativos a ideias e concepções genéricas e introdutórias acerca do serviço público; atualizações sobre alguns aspectos legais envolvidos em ativida- 
des realizadas pelos servidores; upgrades sobre sistemas operacionais utilizados na UFBA; e desenvolvimento de competências gerenciais, perfil este, no mais das vezes, pouco útil ao contexto profissional e pessoal dos envolvidos. Com tal caracterização, distanciam-se do indicado por alguns dos estudiosos antes referenciados.

Segundo relato da equipe do NUCAP, a falta de alinhamento entre essas duas importantes dimensões organizacionais, como indicado por Bergue (2011), Oliveira Filho (2012), Bregalda, Tosta e Dalmau (2014), Ayres (2012, 2015) e Cardoso (2017), é fortalecida pela falta de diretrizes estratégicas claras no PDI da UFBA em relação ao que se espera para a qualificação do quadro de servidores técnicos. Tal cenário faz com que seja difícil para as unidades de ensino e administrativas direcionar melhor suas solicitações de capacitação nos LNC, fazendo com que se tenha a oferta de um mix de cursos padronizados e pouco aderentes às necessidades da organização e dos servidores, fato agravado pela não explicitação nos PAC das metas a serem atingidas pela capacitação.

No que se refere à seleção dos servidores, em consonância com as dimensões contempladas no modelo 5W2H detalhado em Pacheco et al. (2008), para participar das ações de capacitação, busca-se, sob a perspectiva da equipe do NUCAP, alinhar-se ao máximo as inscrições/seleção às atividades desenvolvidas pelo servidor solicitante da vaga. Assim, em cursos de conteúdo mais generalista, funcional e utilizados em diversos ambientes organizacionais, a exemplo de línguas, informática, preparatórios para seleção em programas de pós-graduação, entre outros, prevalece a ordem cronológica da realização de inscrição, com vistas a se dirimir ao máximo a possibilidade de se privilegiar um TAE em detrimento de outro, mitigando-se, assim, eventuais conflitos entre os interessados e entre estes e o NUCAP. Para os demais, o desenvolvimento de competências específicas é sempre um fator de escolha.

Especificamente em relação ao início da oferta de ações de capacitação voltadas à melhoria dos níveis de educação formal do corpo funcional, apenas a partir do PAC de 2012 a UFBA lança o primeiro edital de auxílio a tal tipo de qualificação. Nessa iniciativa, a organização passou a conceder auxílio financeiro aos servidores matriculados em cursos, e ofertou-se em parceria com a Escola de Administração da UFBA a primeira turma de especialização exclusiva para os TAEs e, em 2016, dando continuidade a essa parceria, teve-se a primeira turma de Mestrado Profissional voltada a esse público-alvo.

Com tais características, defende-se neste artigo que, na prática, os PAC, até este momento, em muitas das ações operacionalizadas, mais do que capacitar servidores com foco nos objetivos estratégicos da UFBA, têm servido como uma compen- 
sação financeira para a progressão deles, uma vez que ao participarem de seminários, congressos e cursos de educação formal nos níveis de graduação e pós-graduação terão ganhos em termos de remuneração. Tal concepção decorre da percepção de que permanece a quase total falta de alinhamento entre a estratégia organizacional e o modelo de capacitação operacionalizado, refletindo uma situação diversa da apontada como adequada por autores diversos, a exemplo de Oliveira Filho (2012), Bregalda, Tosta e Dalmau (2014), Ayres (2012, 2015) e Cardoso (2017).

No processo de operacionalização da capacitação dos TAEs, tem-se, ainda em consonância com o modelo 5W2H, uma avaliação em dois momentos distintos das ações implementadas: antes e ao final dos cursos. A primeira visa identificar as expectativas dos participantes em relação ao processo, sendo, para tal, aplicado um questionário composto por questões que exploram dimensões inerentes aos anseios individuais acerca do conteúdo contemplado, assim como sobre sua adequação e aplicabilidade ao contexto profissional prático do participante. Na segunda avaliação, aplicada ao final do curso, busca-se, também por meio de um questionário, identificar-se a visão crítica dos concluintes acerca da qualidade do instrutor, a adequação da carga horária ao conteúdo trabalhado, a infraestrutura de apoio e a atuação da equipe do NUCAP.

Assim, sob uma perspectiva mais crítica, percebe-se, mais uma vez, a falta de um modelo de avaliação mais amplo, o qual permita que se verifiquem os reais impactos institucionais da capacitação, uma vez que os gestores não são ouvidos sobre os efeitos dela sobre as atividades realizadas pelos TAEs a eles subordinados, direta e indiretamente, ou seja, novamente tem-se a presença de um modelo de capacitação desalinhado das demandas organizacionais, fazendo com que o processo perca em muito sua força e potencialidade de transformação organizacional, como preconizado em Amaral (2006), Pacheco et al. (2008), Schikmann (2010) e pela própria PNDP.

Um ponto positivo a ser ressaltado no sentido de mitigar esse problema consiste, segundo relato do chefe do NUCAP, no fato de que se encontra em elaboração um projeto piloto de avaliação de impacto. Tal projeto tem por objetivo mensurar a efetividade das ações de capacitação na melhoria da qualidade do serviço desempenhado pelo egresso, como indicado por Pacheco et al. (2008); contudo não há ainda um prazo definido para a sua operacionalização.

Avançando-se na análise temporal dos PAC da UFBA, verifica-se também a falta de uniformidade no quantitativo dos servidores certificados nos cursos de capacitação ofertados. Segundo informações da equipe do NUCAP, essa oscilação no número de servidores capacitados por cursos ofertados em cada PAC decorre, principalmente, das greves da categoria ocorridas nos anos 2011, 2013 e 2015. Em outras 
palavras, na avaliação da equipe responsável pela operacionalização das iniciativas institucionais de capacitação, a desmobilização da força de trabalho, fruto dos movimentos grevistas teve impactos diretos na evasão e absenteísmo nos cursos, levando, inclusive, ao cancelamento de muitas das ações previstas. Essa situação pode ser melhor visualizada a partir do Gráfico a seguir apresentado.

Gráfico 1 - Número de servidores capacitados por PAC

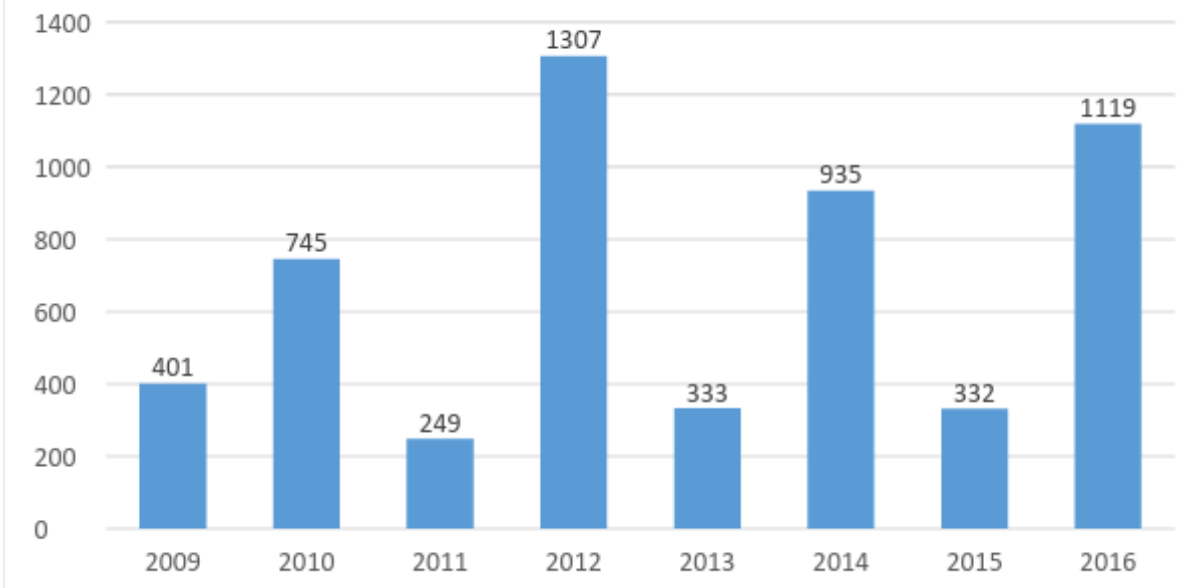

Fonte: elaborado pelos autores a partir dos dados dos relatórios de execução do PAC.

Considerando que o quantitativo médio do número total de servidores no recorte temporal estudado ficou em 3.235 TAEs, pode-se afirmar que nos anos em que houve mais servidores capacitados por ações do PAC o índice atingiu o máximo de 40,4\% de servidores atendidos. Nos anos de greve da categoria, esse índice caiu para até $10,3 \%$ do total de servidores capacitados, confirmando-se as percepções dos funcionários do NUCAP. Prosseguindo-se na análise do modelo de capacitação da UFBA, apresentam-se a seguir algumas reflexões sobre os relatórios de gestão à luz da PNDP.

\subsection{ANÁLISE DOS RELATÓRIOS DE GESTÃO: IMPACTOS DA PNDP}

Além dos números trazidos pelas ações de capacitação resultantes da execução dos PAC, a implementação da PNDP na UFBA teve por objetivo promover a mudança gradual do perfil do corpo técnico-administrativo da instituição do ponto de vista da educação formal, adequando-se, assim, ao indicado por diferentes autores, a exemplo de Pacheco et al. (2008), Schikmann (2010) e Bergue (2011). 
Ademais, a possibilidade de desenvolvimento na carreira e o retorno financeiro resultantes da certificação em eventos de capacitação previstos pela Lei n. 11.091/2005 levaram muitos servidores a realizarem, além dos cursos ofertados pelo PAC, outras qualificações por iniciativa própria fora da UFBA. Vale ressaltar que a referida legislação prevê incentivos financeiros que vão de 10 a 75\% da remuneração básica do cargo do servidor para tal fim.

No que se refere à capacitação na carreira, segundo o plano de carreira da categoria, é possível ao servidor avançar até três níveis, fazendo jus a uma elevação da remuneração correspondente a 3,9\% para cada um deles. O avanço nos níveis funcionais do plano de carreira ocorre com a certificação do servidor por meio de ações de capacitação diversas com cargas horárias totais que podem variar de 60 a 180 horas com os chamados cursos de extensão. Naturalmente, as recentes ofertas de especializações e mestrado profissional também qualificam os servidores à progressão funcional após o seu término. O próximo Gráfico ilustra a evolução dos indicadores de escolaridade dos TAEs da UFBA, ao longo do período analisado no escopo do artigo.

\section{Gráfico 2 - Número de TAEs por nível de escolaridade}

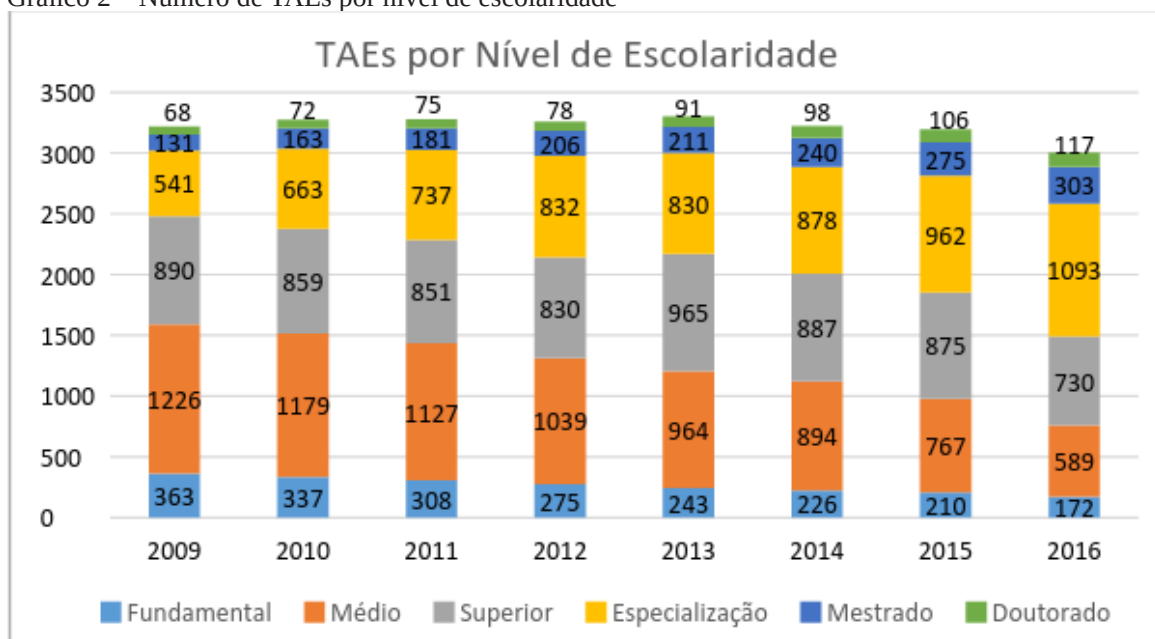

Fonte: elaborado pelos autores a partir dos dados dos relatórios de gestão da PRODEP.

Nota-se, da análise da série histórica de sete anos, o crescimento sistemático do nível de educação formal do corpo técnico-administrativo da UFBA, com destaque para o crescimento de mais de $100 \%$ do número de servidores que possuíam especialização no período 2009-2016. Chama a atenção também para o quantitativo de mestres e doutores, que teve aumento expressivo. Tal quantitativo pode ter relação 
com a oferta anual, a partir de 2011, de cursos sobre elaboração de projeto de pesquisa, metodologia científica, que foram agregados, a partir do PAC 2016, no Programa de preparação para processos seletivos de pós-graduação. Em relação à evolução dos servidores na carreira, o Gráfico a seguir apresenta as modificações dos níveis de capacitação.

Gráfico 3 - Número de TAEs por níveis de capacitação na carreira

TAEs por Nível de Capacitação

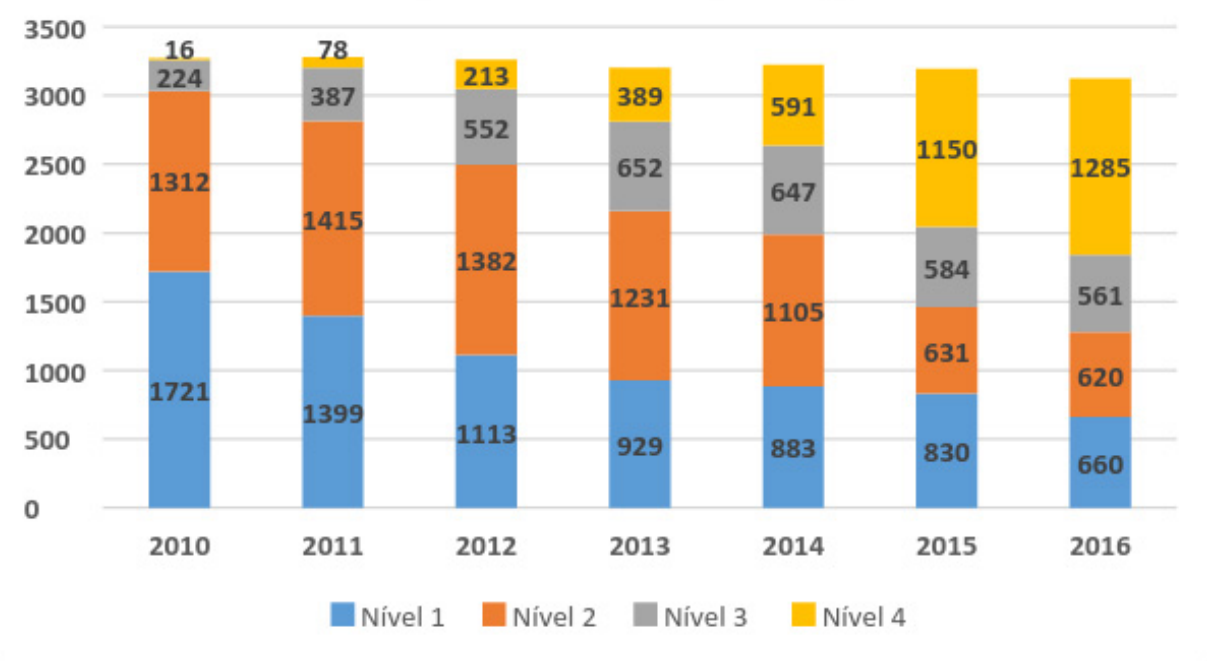

Fonte: elaborado pelos autores a partir dos dados dos relatórios de gestão da PRODEP.

A análise dos dados dessa série histórica demonstra que o número de servidores sem nenhuma capacitação, que correspondia a 52,6\%, passou a 26\% do total de TAEs, enquanto o número de servidores no último nível alcançou $41 \%$ da força de trabalho ante um índice de 0,48\% em 2011. Salienta-se que a carreira dos TAEs, prevista na Lei n. 11.091, é dividida em cinco classes de cargos com a escolaridade mínima de ingresso: classe A, cargos com exigência de nível fundamental incompleto; classe B, com exigência de nível fundamental completo; classe C, com nível médio incompleto; classe D, com requisito mínimo de ensino médio completo; e classe E, com exigência de nível superior completo. Para cada classe de cargo, há o avanço do servidor em três níveis via certificação em ações de capacitação: nível 1, inicial e quando o servidor não possui nenhuma capacitação, e níveis 2, 3 e 4, em que o funcionário progride ao se capacitar.

Pontua-se que, para fazer jus a tal progressão, os eventos de capacitação nos quais o TAE tenha participado e logrado certificação precisam ter carga horária míni- 
ma de 20 horas para que possam ser acumuladas no interstício de 18 meses, perfazendo cargas horárias totais no período citado de 60 a 180 horas, a depender do nível de capacitação e da classe à qual o servidor esteja posicionado na carreira.

Com isso, infere-se que os estímulos oferecidos pela PNDP e pelo Plano de Carreira têm levado os TAEs da UFBA a investirem na participação em vários eventos de capacitação, sejam eles oferecidos pela própria Instituição, sejam eles realizados por iniciativa própria em cursos oferecidos pelo mercado, ainda que não seja possível identificar as contribuições mais efetivas desses investimentos e esforços à UFBA.

\subsection{A VISÃO DA EQUIPE DO NUCAP}

Segundo relato da equipe do NUCAP, o principal motivo que tem levado o servidor da UFBA a buscar os cursos de capacitação ainda é o incremento salarial provocado pela mudança de nível previsto na carreira, sendo vistos como excepcionais alguns cursos para determinados cargos ou atividades, a exemplo de profissionais de saúde (enfermeiros, farmacêuticos e laboratoristas), que além de possuírem tradição em educação continuada para o trabalho, passam por mudanças de procedimentos de forma muito frequente por conta dos avanços práticos na área.

Entretanto, ainda segundo esse grupo, contrariando o preconizado por $\mathrm{Pa}$ checo et al. (2008), Oliveira Filho (2012), Bregalda, Tosta e Dalmau (2014), Ayres (2012, 2015) e Cardoso (2017), com o incremento do número de servidores no último nível de capacitação previsto no plano de carreira da categoria, tem aumentado o quantitativo de TAEs da Instituição que buscam os eventos de capacitação para melhoria de habilidades pessoais e satisfação pessoal, principalmente em cursos preparatórios voltados à participação desses servidores em processos seletivos de cursos de pós-graduação nos níveis de mestrado e doutorado.

A ausência de diretrizes estratégicas que pudessem direcionar melhor a oferta das ações de capacitação para o que se espera em termos de planejamento estratégico organizacional foi um ponto recorrente no relato do chefe do NUCAP, fazendo, assim, com que o modelo adotado pela UFBA se afaste dos objetivos da PNDP e dos pressupostos trazidos pelos autores citados no parágrafo anterior. Segundo esse profissional, o PDI da instituição não traz elementos que possam ser desdobrados em um plano de ação com metas a serem atingidas e áreas prioritárias de atendimento via capacitação, gerando dificuldades que vão desde aquelas mais simples, a exemplo da liberação dos servidores para participar dos cursos ofertados, até a avaliação dos efeitos reais das ações de capacitação no desempenho das atividades laborais do servidor. 
Outra limitação apontada pela equipe do NUCAP diz respeito à ausência de subsídios para a capacitação, fornecidos pela avaliação de desempenho realizada a cada um ano e meio com os servidores. Ou seja, mais uma vez há falta de aderência ao apontado por teóricos diversos, a exemplo de Pacheco et al. (2008), Oliveira Filho (2012), Bregalda, Tosta e Dalmau (2014), Ayres (2012, 2015) e Cardoso (2017). De acordo com a equipe, a avaliação realizada possui um cunho meramente normativo, visando simplesmente ao cumprimento de exigências legais. Assim, esse poderoso instrumento termina, por seu caráter meramente ritualístico e formal, perdendo sua força e não apontando de forma devida as lacunas de formação que deveriam ser preenchidas por meio de oferta de cursos de capacitação.

Apesar desse cenário pouco promissor em termos da operacionalização de um processo de capacitação institucional na UFBA, há que se destacar a presença de alguns avanços ao longo do período aqui estudado. Entre eles, segundo a equipe do NUCAP, há, em consonância com alguns pressupostos da PNDP, reforçados por Oliveira Filho (2012), Camões (2013), Bregalda, Tosta e Dalmau (2014) e Cardoso (2017), a melhoria promovida na comunicação do núcleo com os servidores, com a implantação do portal eletrônico de divulgação dos eventos de capacitação; do aprimoramento nos processos de inscrição dos servidores nos eventos, processo que passou a ocorrer por meio de um sistema informatizado que facilitou o acesso dos TAEs; e com a implantação pela UFBA de um sistema integrado de gestão informatizado, o qual permitiu a melhora da geração e do acesso por parte da equipe de gestão da PRODEP às informações e relatórios relativos ao desenvolvimento e à gestão de pessoas na Instituição, facilitando a instrumentalização da equipe para o planejamento e a tomada de decisão em relação às ações de capacitação.

A seguir, apresentam-se algumas considerações finais acerca do estudo realizado, bem como suas limitações e possíveis trabalhos futuros.

\section{CONSIDERAÇÕES FINAIS}

Neste trabalho visou-se, a partir da caracterização do processo de capacitação dos servidores TAEs da UFBA, à luz da PNDP, analisar o modelo adotado pela Instituição e a evolução dos indicadores relacionados a tal dimensão no período de 2009 a 2016, considerando-se nesse processo analítico concepções apresentadas por diferentes teóricos que se debruçam sobre tal temática, no contexto nacional.

A partir da análise dos dados coletados na pesquisa documental, observação e entrevistas informais com a equipe do NUCAP, compreendeu-se como ocorreu o 
processo de capacitação na Instituição no período delimitado, respondendo à questão que motivou o estudo. Os achados também confirmaram o pressuposto da pesquisa, demonstrando que as ações de capacitação ofertadas pela UFBA pouco se aproximam dos objetivos organizacionais, tendo por foco o aprimoramento de competências de natureza funcional, o atendimento da demanda legal e respondendo à expectativa de melhoria remuneratória prevista no plano de carreira dos TAEs.

Contudo, identificou-se, mediante a análise dos PAC, no intervalo 20092016, avanços obtidos com a implementação da PNDP na IFES. Houve incremento no quantitativo de eventos de capacitação, ainda que houvesse oscilações provocadas por fatores como greves. Foram relatados pela equipe do NUCAP alguns problemas de ordem operacional e estrutural da UFBA, entre eles a ausência de diretrizes estratégicas claras para a área e as dificuldades metodológicas na realização dos LNC, o que confirma indicações apresentadas por muitos dos teóricos que ancoraram conceitualmente a construção do artigo.

A análise dos relatórios da PRODEP desvelou que o principal impacto da PNDP na Instituição foi a mudança do perfil do corpo técnico-administrativo da UFBA do ponto de vista da educação formal e do nível de capacitação na carreira. Houve melhoria significativa do nível de educação formal dos TAEs, reduzindo-se o percentual de 49,36\% com até o ensino médio completo, para apenas 25,33\%, demonstrando-se, assim, o aumento dos profissionais com nível superior. Além disso, verificou-se que $41 \%$ dos TAEs estão no nível mais alto de capacitação previsto no plano de carreira da categoria.

Entre os principais problemas, conforme o que apontam autores a exemplo de Schikmann (2010), Oliveira Filho (2012), Pantoja et al. (2012), Camões (2013), Bregalda, Tosta e Dalmau (2014), os relatos da equipe de capacitação destacam a lacuna da prática de planejamento estratégico na Instituição e a falta de dados para a capacitação decorrente de um processo de avaliação de desempenho de caráter normativo.

Diante de tal contexto, propõe-se que seja implementado um sistema de avaliação de desempenho efetivo que possa aferir em que medida as capacitações realizadas pelos servidores TAEs são aplicáveis e aplicadas aos contextos do exercício de suas atividades laborais. Além disso, sugere-se que a Universidade inclua no seu planejamento estratégico diretrizes e metas que possam balizar mais efetivamente o desenvolvimento de uma política de capacitação aderente aos objetivos institucionais, em consonância com diversos autores apresentados e PNDP.

Considera-se, aqui, que os resultados apresentados demonstraram que a UFBA ainda se encontra em um estágio de mudança de cultura organizacional e as- 
similação de novas práticas de gestão de pessoas referente ao modelo de capacitação adotado, ainda distante do preconizado por Bresser-Pereira (2007, 2009) e Abrucio (2007, 2011), no que se refere à necessidade da adoção do modelo gerencialista na administração pública direta e indireta no Brasil.

Finaliza-se o artigo considerando-se que ele possui como limitação básica a exploração de um tema complexo à luz das visões de um pequeno número de atores e de documentos oficiais. Por conta disso, sugere-se que sejam realizados estudos futuros que identifiquem as percepções dos gestores e dos TAEs acerca das capacitações ofertadas pela Instituição ao seu corpo técnico-administrativo, assim como se realizem estudos similares em outras IFES. Dessa forma, acredita-se que a contribuição teórica aqui apresentada em relação ao entendimento do processo de capacitação dessa IFES possa contribuir, de forma sistematizada, para a melhor compreensão desse fenômeno no segmento do ensino superior federal.

\section{REFERÊNCIAS}

ABRUCIO, F. L. Trajetória recente da gestão pública brasileira: um balanço crítico e a renovação da agenda de reformas. RAP - Revista Brasileira de Administração Pública, v. 1, p. 77-87, 2007. Disponível em: <http://gvpesquisa.fgv.br/sites/gvpesquisa.fgv.br/files/arquivos/abrucio_-_trajetoria_recente_da_gestao_publica.pdf $>$. Acesso em: 15 nov. 2017.

ABRUCIO, F. L. Três agendas, seus resultados e um desafio: balanço recente da administração pública federal brasileira. Desigualdade \& Diversidade, v. 11, p. 119-142, dez. 2011. Disponível em: <http://gvpesquisa.fgv.br/sites/gvpesquisa.fgv. br/files/arquivos/fernando_abrucio_-_3agendas.pdf>. Acesso em: 15 nov. 2017.

ALMEIDA, L. R. de; BRAUER, M.; PINHEIRO JÚNIOR, L. Capacitação na Gestão Pública: Revisitando as Publicações das Bases Spell e Anpad sobre o Tema. In: INOVARSE-FIERJ, 2017, Rio de Janeiro. Anais... Rio de Janeiro, 2017.

AMARAL, H. K. do. Desenvolvimento de competências de servidores na administração pública brasileira. RSP - Revista do Serviço Público, Brasília, DF, v. 57, n. 4, p. 549-563, 2006. Disponível em: <https://revista.enap.gov.br/index.php/RSP/ article/download/211/216>. Acesso em: 14 jul. 2017. 
AYRES, S. M. P. M. Proposta de um sistema de capacitação baseada em competências para o Instituto Federal de Educação Ciência e Tecnologia do Sertão Pernambucano. 2012. Dissertação (Mestrado Acadêmico em Administração)-Universidade Federal da Paraíba, João Pessoa, 2012. Disponível em: http://repositorio. unb.br/bitstream/10482/4295/1/2009_RodrigoRezendeFerreira.pdf <http://www. ccsa.ufpb.br/ppga/site/arquivos/dissertacoes/dissertacao_516.pdf > . Acesso em: 15 nov. 2017.

AYRES, S. M. P. M. Sistema de Capacitação Baseado em Competências - SCBC. In: Gestão de pessoas por competências nas Instituições Federais de Ensino (IFE). João Pessoa: Paraíba, 2015.

BERGUE, S. T. Modelos de gestão pública em organizações: teorias e tecnologias para análise e transformação organizacional. Caxias do Sul: Educs, 2011.

BRASIL. Decreto n. 5.707, de 23 de fevereiro de 2006. Disponível em: < http:// www.planalto.gov.br/ccivil_03/_ato2004-2006/2006/decreto/d5707.htm>. Acesso em: 15 nov. 2017.

BRASIL. Lei n. 11.091, de 12 de janeiro de 2005. Disponível em: <http://www.planalto.gov.br/ccivil_03/_ato2004-2006/2005/lei//11091.htm>. Acesso em: 15 nov. 2017.

BREGALDA, A.; TOSTA, A. T.; DALMAU, M. B. L. A Política Nacional de Desenvolvimento de Pessoas e sua implantação em duas instituições federais de ensino brasileiras. In: COLÓQUIO INTERNACIONAL DE GESTÃO UNIVERSITÁRIA CIGU, 14., 2014, Florianópolis. Anais... Florianópolis, dez. 2014. p. 1-17. Disponível em: <https://repositorio.ufsc.br/xmlui/bitstream/handle/123456789/131672/2014-115. pdf?sequence=1\&isAllowed=y $>$. Acesso em: 15 nov. 2017.

BRESSER-PEREIRA, L. C. Burocracia pública e Estado no Brasil. RERE - Revista Eletrônica sobre a Reforma do Estado, Salvador, n. 11, p. 1-65, set./nov. 2007. Disponível em: <http://www.direitodoestado.com/revista/RERE-11-SETEMBRO-2007-BRESSER\%20PEEREIRA.pdf>. Acesso em: 15 nov. 2017.

BRESSER-PEREIRA, L. C. Construindo o Estado republicano: democracia e reforma da gestão pública. Rio de Janeiro: Ed. FGV, 2009. 
CAMÕES, M. R. S. Análise do processo de implementação da Política Nacional de Desenvolvimento de Pessoal. 2013. 200 p. Dissertação (Mestrado em Administração)-Universidade de Brasília, Brasília, DF, 2013. Disponível em: <http://repositorio.unb.br/bitstream/10482/13586/1/2013_MarizauraReisdeSouzaCam\%c3\%b5es. pdf>. Acesso em: 15 nov. 2017.

\section{CARDOSO, S. P. Q. C. Capacitação dos técnicos administrativos com base na} gestão de pessoas por competências - o caso do IF Sertão-PE. 2017. 160 p. Dissertação (Mestrado em Administração)-Universidade Federal da Bahia, Salvador, 2017.

CAVALCANTE, J. C. A. et al. Capacitação de servidores públicos: uma análise dos eixos da política implantada na UFAL. In: CONGRESSO NACIONAL DE MESTRADOS PROFISSIONAIS EM ADMINISTRAÇÃO PÚBLICA, 1., 2016, Curitiba. Anais... Curitiba, 2016. Disponível em: <http://www.profiap.org.br/profiap/eventos/2016/i-congresso-nacional-de-mestrados-profissionais-em-administracao-publica/anais-do-congresso/41423.pdf> . Acesso em: 10 nov. 2017.

GIL, A. C. Como elaborar projetos de pesquisa. São Paulo: Atlas, 2002.

GIL, A. C. Métodos e técnicas de pesquisa social. São Paulo: Atlas, 2007.

GODOY, A. S. Introdução à pesquisa qualitativa e suas possibilidades. RAE, São Paulo, v. 35, n. 2, p. 57-63, mar./abr. 1995. Disponível em: <http://www.scielo.br/ pdf/rae/v35n2/a08v35n2.pdf>. Acesso em: 15 nov. 2017.

GUIMARÃES. T. A. A nova administração pública e a abordagem da competência. RAP, Rio de Janeiro, v. 34, n. 3, p. 125-140, 2000. Disponível em: <http://bibliotecadigital.fgv.br/ojs/index.php/rap/article/download/6284/4875>. Acesso em: 02 jul. 2017.

LUBISCO, N. M. L.; VIEIRA, S. C. Manual de estilo acadêmico: trabalhos de conclusão de curso, dissertações e teses. Salvador: EDUFBA, 2013.

OLIVEIRA FILHO, A. Política de gestão de pessoas em instituições federais de ensino superior: uma análise dos subsistemas capacitação e aperfeiçoamento e avaliação de desempenho. 2012. Dissertação (Mestrado em Administração)-Universidade Federal de Santa Catarina, Florianópolis, 2012. Disponível em: <https:// repositorio.ufsc.br/xmlui/bitstream/handle/123456789/100675/309616.pdf?sequence=1\&isAllowed=y > . Acesso em: 12 jul. 2017. 
PACHECO, L. et al. Capacitação e desenvolvimento de pessoas. Rio de Janeiro: Ed. FGV, 2008.

PANTOJA, M. J. et al. Política nacional de desenvolvimento de pessoal na administração pública federal: uma caracterização da capacitação por competências na administração pública federal. In: CONGRESSO CONSAD, 5., 2012, Brasília, DF. Anais... Brasília, DF, 2012. Disponível em: <http://banco.consad.org.br/bitstream/123456789/789/1/C5_TP_POL\%C3\%8DTICA\%20NACIONAL\%20DE\%20 DESENVOLVIMENTO\%20DE\%20PESSOAL.pdf>. Acesso em: 15 nov. 2017.

SCHIKMANN, R. Gestão estratégica de pessoas: bases para a concepção do Curso de Especialização em Gestão de Pessoas no Serviço Público. In: Gestão de Pessoas: bases teóricas e experiências no setor público. Brasília, DF: ENAP, 2010.

SIQUEIRA, M. V. S.; MENDES, M. M. Gestão de pessoas no setor público e a reprodução do discurso do setor privado. RSP - Revista do Serviço Público, Brasília, DF, v. 60, n. 3, p. 241-260. jul./set. 2009. Disponível em: <https://revista.enap.gov. br/index.php/RSP/article/view/25>. Acesso em: 15 nov. 2017.

TEIXEIRA FILHO, A. R. C.; ALMEIDA, D. R. Gestão por competências: mapeamento de competências na Universidade Federal da Bahia. In: COLÓQUIO INTERNACIONAL DE GESTÃO UNIVERSITÁRIA - CIGU, 14., 2014, Florianópolis. Anais... Florianópolis, 2014. p. 1-17. Disponível em: <https://repositorio.ufsc.br/ bitstream/handle/123456789/131380/2014-22.pdf?sequence=1\&isAllowed=y $>$. Acesso em: 03 jun. 2017.

YIN, R. K. Estudo de caso: planejamento e métodos. Porto Alegre: Bookman, 2005.

\section{Como citar este artigo:}

ABNT

TEIXEIRA FILHO, Antônio Raimundo Cardoso et al. Capacitação no setor público: analisando o processo de uma IFES. RACE, Revista de Administração, Contabilidade e Economia, Joaçaba: Ed. Unoesc, p. 185-208, 2017. Edição Especial. Disponível em: <http://editora.unoesc.edu.br/index.php/race>. Acesso em: dia/mês/ano.

\section{APA}

Teixeira Filho, A. R. C., Almeida, D. R., Almeida L. R., \& Almeida, S. M. V. (2017). Capacitação no setor público: analisando o processo de uma IFES [E. especial]. RACE, Revista de Administração, Contabilidade e Economia, 185-208. Recuperado em dia/mês/ano, de http://editora.unoesc.edu.br/index.php/race 